\title{
STRANGE TEMPERATURE CHARACTERISTICS OF RUO2-BASED THICK FILM RESISTORS
}

\author{
TOSHIO INOKUMA \\ Shoei Chemical Inc. 2-6-1 Nishi-Shinjuku, Shinjuku-ku, Tokyo Japan \\ YOSHIAKI TAKETA and MIYOSHI HARADOME \\ Physical Science Laboratories, Nihon University, 1-2-1 Izumicho, Narashino, Chiba-ken, Japan
}

Received December 24 1981; in final form February 121982

\section{INTRODUCTION}

One of the most desirable characteristics of a resistor is temperature independency. The resistance values of almost all the resistors, however, change by self-heating and/or by a fluctuation of atmospheric temperature. The temperature coefficient of resistor (TCR) becomes larger as the resistance decreases, especially in thick film resistors. ${ }^{1}$ Therefore, the improvement of this property has been greatly desired and various kinds of methods of getting TCR zero are being investigated now. For example, in the case of thick film resistors, there is a method of doping some materials such as $\mathrm{CuO}, \mathrm{CdO}, \mathrm{Fe}_{2} \mathrm{O}_{3}$, etc. with conductive elements or glass frits. ${ }^{2}$

In some experiments on improving the electrical properties of the thick film resistors, we have found that some, the TCRs of which are nearly zero, can be made easily by doping with $\mathrm{MnO}_{2}$ the conductive element $\mathrm{RuO}_{2}$ of the thick film resistors, and this $\mathrm{MnO}_{2}$-doped resistor posesses a low TCR; they all have the same low TCR, from low to high resistivity.

\section{EXPERIMENTS AND RESULTS}

The composition and the preparation of the specimens used in this study is as follows. The main conductive element of the resistor was $\mathrm{RuO}_{2}$ powder having an average particle size of $370 \mathrm{~A}$. To this $\mathrm{RuO}_{2}$ was added in various ratios. The ratio of dopant to the conductive element was varied between zero and $12 \mathrm{wt} \%$. The composition of the glass frits was $52 \mathrm{PbO}-35 \mathrm{SiO}_{2}-10 \mathrm{~B}_{2} \mathrm{O}_{3}-3 \mathrm{Al}_{2} \mathrm{O}_{3}$ in weight percent (wt\%) ratio and had a softening point at $600^{\circ} \mathrm{C}$, specific gravity of $3.74 \mathrm{~g} / \mathrm{cm}^{3}$, and average diameter of particles of $3 \mu \mathrm{m}$.

The conductive powders were mixed with the glass frits at $\mathrm{RuO}_{2}$ to Glass $=50: 50,25: 75,15: 85$ and 10:90 in wt $\%$ ratio. Then the powdered mixtures of conductive materials and glass frits were evenly dispersed into some organic vehicles to produce printable thick film resistor pastes. Resistor pastes having four kinds of resistivity were obtained. The resistivity of each resistor paste was about $20 \Omega /$ sq. at a mixing ratio of $50: 50,500 \Omega /$ sq. at $25: 75,4 \mathrm{k} \Omega / \mathrm{sq}$. at $15: 85$ and $30 \mathrm{k} \Omega / \mathrm{sq}$. at $10: 90$, after firing at $850^{\circ} \mathrm{C}$ for 8 minutes. The current noise of the specimen was found to be at a very low level, under $-5 \mathrm{~dB}$.

Before screen printing and firing of the resistor pastes, AuPt or PdAg thick film conductors were printed on the $96 \%$ alumina substrate. These resistor pastes were printed on the substrates using a 200 mesh stainless screen mask and dried in forced air at $150^{\circ} \mathrm{C}$ for 20 minutes. This was followed by firing at a peak firing temperature of $850^{\circ} \mathrm{C}$ for 8 minutes in an overall $55 \mathrm{~min}$. cycle in a belt furnace. Four different peak firing temperatures, $700^{\circ} \mathrm{C}, 800^{\circ} \mathrm{C}, 850^{\circ} \mathrm{C}$ and $900^{\circ} \mathrm{C}$, were also used to study the firing temperature sensitivity. Throughout, the total firing cycle was kept constant at 55 minutes. In order to examine the interrelated effects of resistor geometry, five kinds of test patterns, $1 \times 0.5 \mathrm{~mm}, 1 \times 1 \mathrm{~mm}, 1 \times 2 \mathrm{~mm}$, $1 \times 4 \mathrm{~mm}$, and $2 \times 4 \mathrm{~mm}$ in area with a thickness of about $12 \mu \mathrm{m}$, were used.

How the content of $\mathrm{MnO}_{2}$ affects the resistivities and TCRs of the specimen was then examined. The results are shown in Figure 1. The relation between hot TCR (room temperature through $125^{\circ} \mathrm{C}$ ) and resistivity in Figure 1 is nearly the same as the characteristics of cold TCR $\left(-55^{\circ} \mathrm{C}\right.$ through room temperature). The tight TCR spread (usually 30 through $50 \mathrm{ppm} /{ }^{\circ} \mathrm{C}$ ) between the hot and cold side average values, is one of the excellent characteristics of this resistor system. Undoped specimens have similar characteristics with respect to the firing temperature variations of $700^{\circ} \mathrm{C}$ through $900^{\circ} \mathrm{C}$ as seen in this figure. This means that the specimens are 

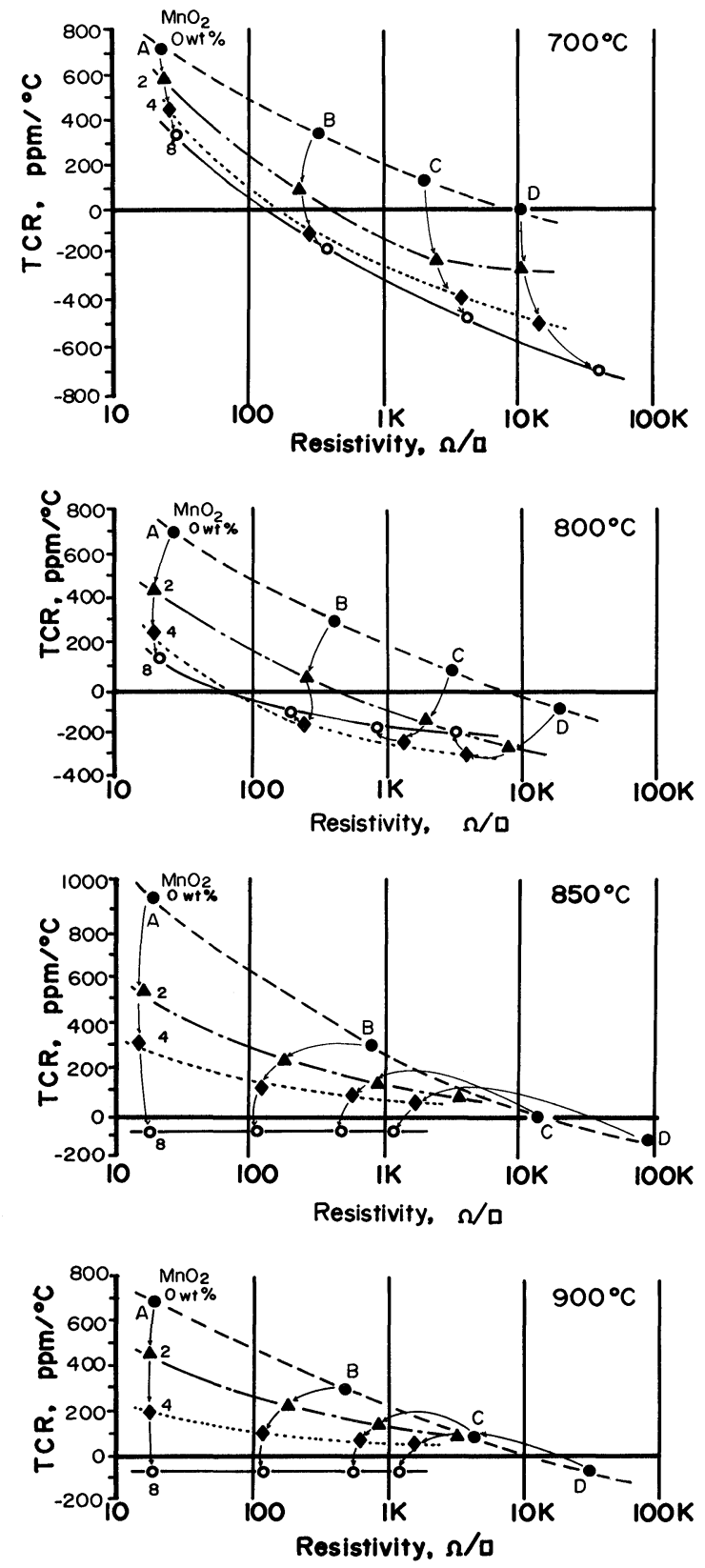

FIGURE 1 Fig. 1 shows the relation between the resistance and TCR of the $\mathrm{MnO}_{2}$ doped $\mathrm{RuO}_{2}$ thick film resistors. (a) firing temperature at $700^{\circ} \mathrm{C}$, (b) $800^{\circ} \mathrm{C}$, (c) $850^{\circ} \mathrm{C}$ and (d) $900^{\circ} \mathrm{C}$. A indicates the mixing ratio $\mathrm{RuO}_{2}$ vs. Glass $=$ 50:50, B 25:75, C 15:85 and D 10:90.

insensitive to the firing temperature. On the other hand the slope of the TCR vs. sheet resistivity curves of the $\mathrm{MnO}_{2}$-doped specimens change considerably with an increase in the content of $\mathrm{MnO}_{2}$ and due to raising the firing temperature. In general, on raising the firing temperature the TCR will shift to less negative and thus more positive value. But, in the case of our specimens, an increase of the firing temperature from $700^{\circ} \mathrm{C}$ to $900^{\circ} \mathrm{C}$ shifts the TCR from positive to negative value. By doping with $\mathrm{MnO}_{2}$ the TCR also shifts to negative values even at the same firing temperature. Higher doping gives more negative values for TCR. The slope of the curves gradually becomes less with a higher content of $\mathrm{MnO}_{2}$.

At a firing temperature of $800^{\circ} \mathrm{C}$ through $900^{\circ} \mathrm{C}$, as the content of $\mathrm{MnO}_{2}$ reaches 5 through $12 \mathrm{wt} \%$, a peculiar phenomenon appears. The curves that express the relation between TCR and resistivity of the specimens run approximately parallel to the horizontal axis indicating a zero value of TCR. This resistor system thus exhibits the same TCR values from low to high resistivity. For instance, a resistor having zero TCR can be produced by doping with 5 through $6 \mathrm{wt} \% \mathrm{MnO}_{2}$ and by firing at $850^{\circ} \mathrm{C}$. TCR values between $20 \Omega / \mathrm{sq}$. and $30 \mathrm{k} \Omega / \mathrm{sq}$. of the resistor are generally within $0 \pm 100 \mathrm{ppm} /{ }^{\circ} \mathrm{C}$. However, given that the content of $\mathrm{MnO}_{2}$ is kept constant, an increase of firing temperature from $800^{\circ} \mathrm{C}$ to $900^{\circ} \mathrm{C}$ shifts the TCR by 50 to $100 \mathrm{ppm} /{ }^{\circ} \mathrm{C}$ in the negative direction.

At low resistivity, with a resistor composition ratio of $\mathrm{RuO}_{2}$ to Glass $=50: 50$, the resistance is almost insensitive to the content of $\mathrm{MnO}_{2}$ and the TCRs are close to zero. Both resistance and TCR of higher resistivity materials decrease on increasing the content of $\mathrm{MnO}_{2}$. At the composition ratio $\mathrm{RuO}_{2}$ to Glass $=10: 90$, the resistor exhibits a very great resistance change on adding $\mathrm{MnO}_{2}$. The TRC of $\mathrm{RuO}_{2}$-based thick film resistor varies over a wide range according to the content of $\mathrm{MnO}_{2}$. Thus resistance values having the desired TCR, can be made with ease.

We studied how a resistor having higher resistivity can be made without losing the good TCR characteristics of the specimen. It was determined how the resis-

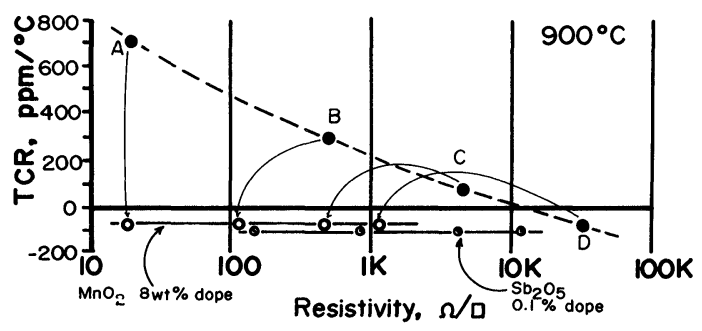

FIGURE 2 Fig. 2 shows the results of how the resistivities and TCRs change by adding $\mathrm{Sb}_{2} \mathrm{O}_{5}$. 
tivities and TCRs change by adding $0.1 \mathrm{wt} \%$ through $0.3 \mathrm{wt} \%$ of $\mathrm{Sb}_{2} \mathrm{O}_{5}$. Figure 2 indicates the results. It was found that the TCRs of $\mathrm{MnO}_{2}$-doped and undoped resistors shift toward negative values from 50 to $150 \mathrm{ppm} /{ }^{\circ} \mathrm{C}$.

The type of conductor and the size of resistor also can have effects. These effects were studied. Our resistor pastes have few geometric effects and have ohmic contact with the electrode. In particular, chemical reactions with the resistor materials and diffusion into them does not occur when PtAu terminals are used. Therefore, one can easily manufacture a very small size resistor having any resistivity. We can thus have a high packaging density on a substrate when this resistor system is used.
Accelerated stability tests are now going on. The resistance drift observed after $1000 \mathrm{hrs}$ of a high temperature test at $150^{\circ} \mathrm{C}$ is within approximately $0.1 \%$.

Further studies, especially of the TCR shift mechanism by $\mathrm{MnO}_{2}$-doping, are being pursued and will be published in the near future.

\section{REFERENCES}

1. A. Callaneo, M. Cocito, F. Forlani and M. Prudenziati; Electrocomponent Science and Tech., 4, 205 (1977). F. Forlani and M. Prudenziati; Electrocomponent Science and Tech., 3, 77 (1976).

2. H.M. Naguib; Proc. 1977 ISHM p. 48. J.S. Shah and W.C. Hahn; Proc. 1978 ISHM p. 234. T.V. Nordstrom and C.R. Hills; Proc. 1979 ISHM p. 40. 

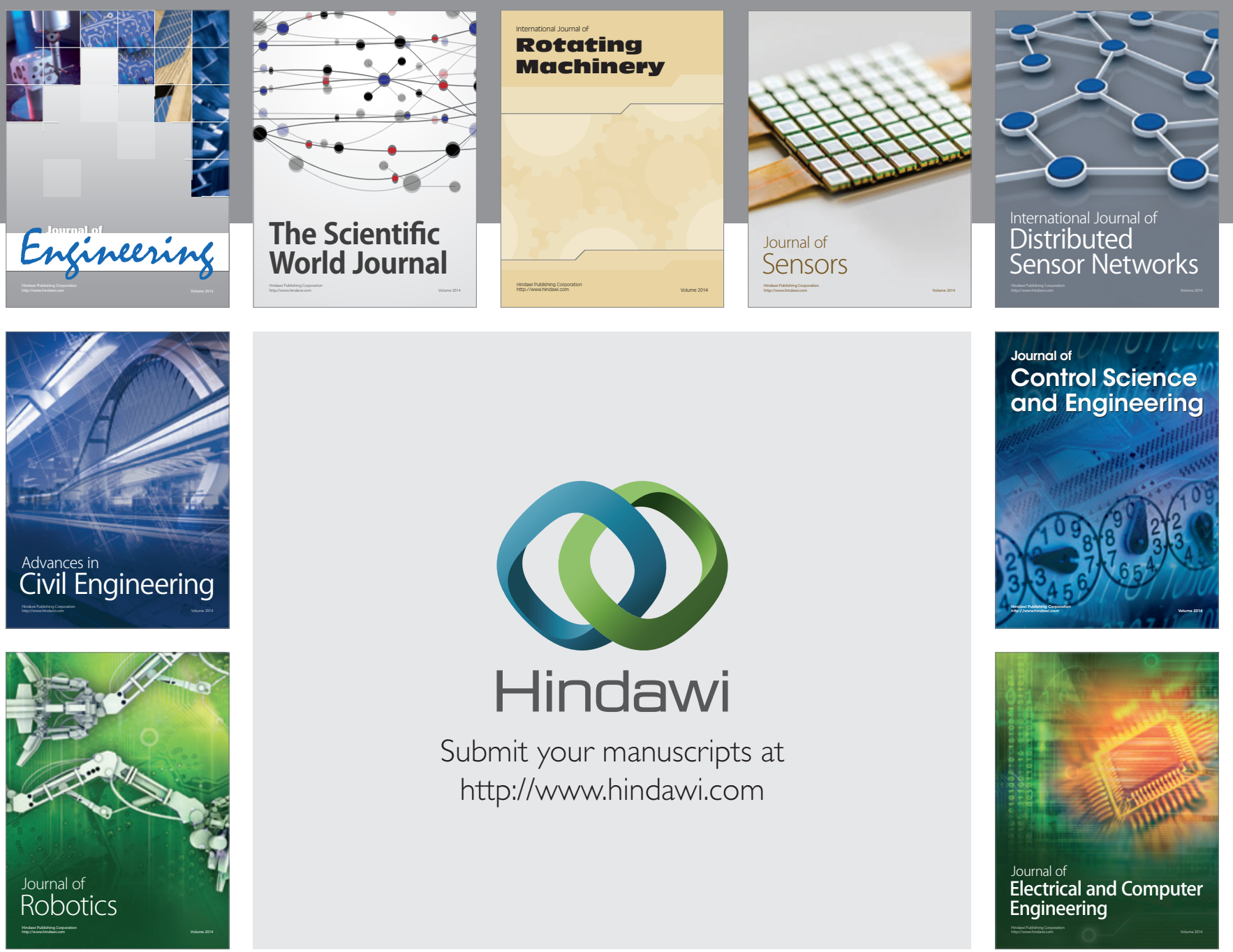

Submit your manuscripts at

http://www.hindawi.com
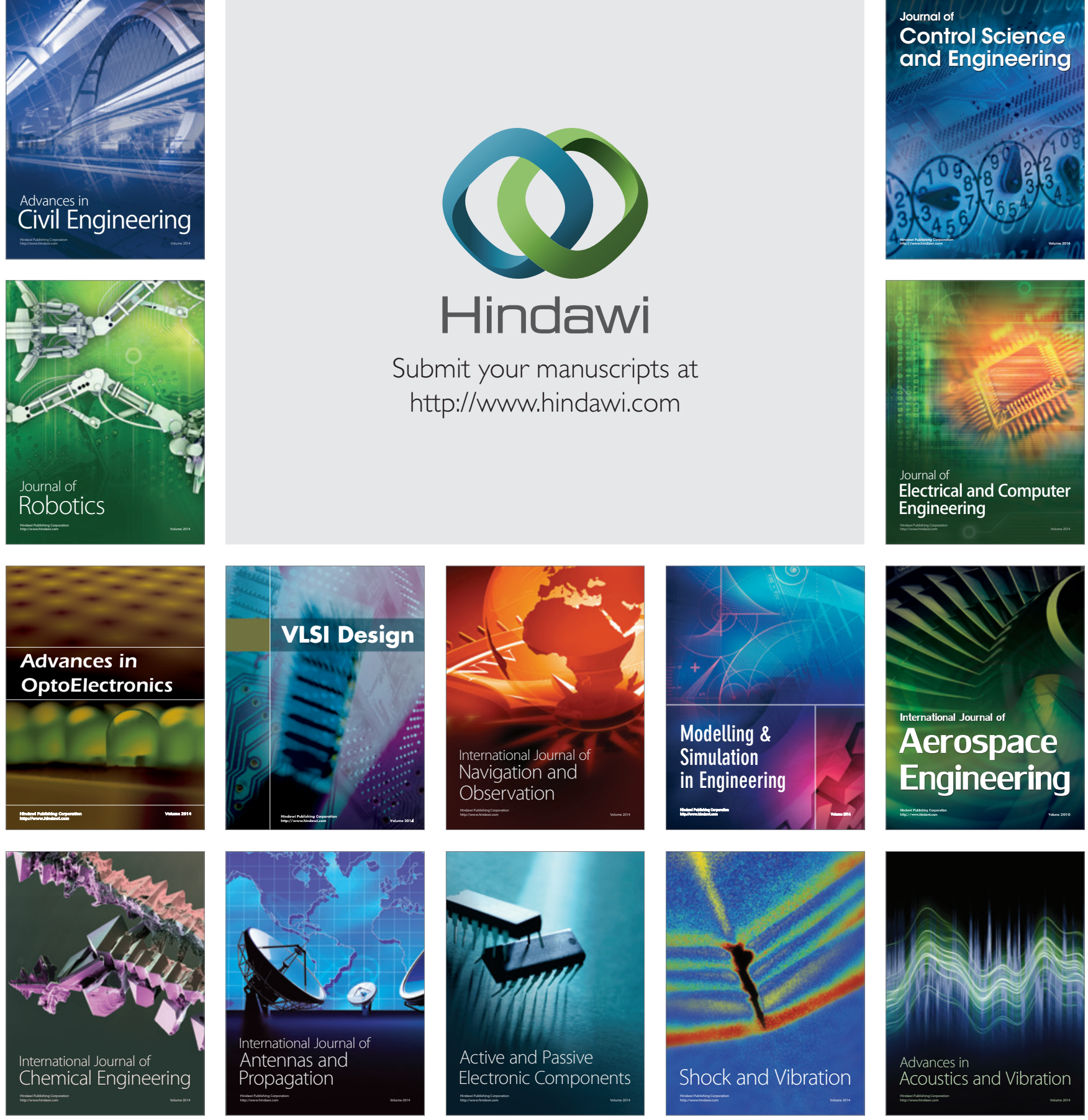